\title{
Clinical outcomes of endoscopic synovectomy with adjuvant radiotherapy of pigmented villonodular synovitis of the hip: a case series of single center
}

Hao sun ${ }^{\dagger}$, Xiao-Dong Ju${ }^{\dagger}$, Hong-Jie Huang, Xin Zhang ${ }^{*}$ and Jian-Quan Wang ${ }^{*}$

\begin{abstract}
Background: Though radiotherapy has been widely used for knee pigmented villonodular synovitis (PVNS), there is few literatures about radiotherapy for the treatment of PVNS hip. Thus, the purpose of this study was to analyze the clinical outcomes of endoscopic synovectomy with/without radiotherapy postoperatively of PVNS hip.

Methods: We performed a retrospective study of patients who underwent endoscopy in our hospital from November 2010 to January 2021. Inclusion criteria was patients with magnetic resonance image (MRI) signs, endoscopic findings and/or histological evidence of PVNS. Exclusion criteria was patients lost follow-up. All patients underwent synovectomy endoscopically and were divided into two groups depending on receiving postoperative radiotherapy or not. The primary outcome measurements were the recurrence of PVNS, receiving revision, and/or converting to total hip arthroplasty (THA). The secondary outcome measurements were the patient-reported outcome (PRO) collected at pre- and post-operation, which consist of Hip Outcome Score Activities of Daily Living (HOS-ADL), modified Harris Hip Score (mHHS), International Hip Outcome Tool-12 (IHOT-12), Non-arthritic Hip Scale (NAHS), and visual analog scale (VAS).
\end{abstract}

Results: In a case series of 16 patients (8 cases of male, 50\%), 4 (25\%) cases were localized type and 12 (75\%) cases were diffuse type. The average follow-up was $44.8 \pm 38.2$ months (range,3 to 110). 8 (50\%) cases (6 diffuse cases and 2 localized cases) received radiotherapy postoperatively, and the rest (6 diffuse cases and 2 localized cases) received endoscopic treatment alone. At the latest follow-up, 3 (18.75\%) cases (2 diffuse cases and 1 localized case) who did not receive radiotherapy converted to arthroplasty. The preoperative HOS-ADL, $\mathrm{mHHS}, \mathrm{HOT}-12$, NAHS, VAS scores of remaining 13 patients were $63.1 \pm 19.1$ (range,32.0 to 98.8), 54.8 \pm 20.1 (range, 10.0 to 77.0 ), $50.9 \pm 15.4$ (range, 31.0 to 76.6), $51.6 \pm 15.9$ (range, 20.0 to 84.4), $6.0 \pm 1.4$ (range,4.0 to 8.0) points, respectively. The latest HOS-ADL, mHHS, IHOT12, NAHS, VAS scores of the 13 patients were $79.7 \pm 10.8$ (range, 58.0 to 97.6), $78.6 \pm 9.1$ (range,55.0 to 87.0), $74.7 \pm 9.7$ (range, 55.6 to 91.0 ), $78.9 \pm 18.7$ (range,20.0 to 92.5), $3.1 \pm 1.2$ (range,2.0 to 6.0) points respectively.

Conclusion: Endoscopic synovectomy can achieve satisfactory PRO in PVNS hip patients. Besides, postoperative adjuvant radiotherapy can achieve higher hip survivability than synovectomy alone in this present study.

\footnotetext{
*Correspondence: tozhangxin@sina.com; wjqsportsmed@163.com

${ }^{\dagger}$ Hao sun and Xiao-Dong Ju contributed equally to this paper as first authors.

Department of Sports Medicine, Peking University Third Hospital; Institute of Sports Medicine of Peking University; Beijing Key Laboratory of Sports Injuries, 49 North Garden Rd, Haidian District, 100191 Beijing, PR China
}

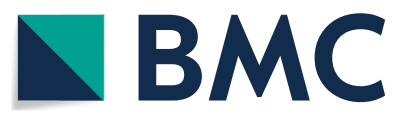

(c) The Author(s) 2022. Open Access This article is licensed under a Creative Commons Attribution 4.0 International License, which permits use, sharing, adaptation, distribution and reproduction in any medium or format, as long as you give appropriate credit to the original author(s) and the source, provide a link to the Creative Commons licence, and indicate if changes were made. The images or other third party material in this article are included in the article's Creative Commons licence, unless indicated otherwise in a credit line to the material. If material is not included in the article's Creative Commons licence and your intended use is not permitted by statutory regulation or exceeds the permitted use, you will need to obtain permission directly from the copyright holder. To view a copy of this licence, visit http://creativecommons.org/licenses/by/4.0/. The Creative Commons Public Domain Dedication waiver (http://creativeco mmons.org/publicdomain/zero/1.0/) applies to the data made available in this article, unless otherwise stated in a credit line to the data. 
Keywords: Pigmented villonodular synovitis, Hip endoscopy, Radiotherapy

\section{Background}

Pigmented villonodular synovitis (PVNS) is a rare, benign disease that is characterized by destructive and recurrent. This disease was first documented by Chassaignac [1]. in 1852, and the lesion was found to be in the flexor tendon sheath of the finger. Later, Jaffe et al. [2] established the pathology of PVNS in 1941. PVNS can not only affect the joints but also can invade peripheral structures including muscle, tendon, bone and skin $[3,4]$. The affected joint is mainly distributed in the knee $(80 \%)$ followed by the hip $(15 \%)[5,6]$. The incidence of PVNS is estimated at 1.8 per million persons [7]. Though PVNS is mostly occurs in middle-aged patients [7], a retrospective multicenter study [8] reported that the youngest case was of a two-year-old, and the oldest, 83 years.

PVNS has no specific symptoms, usually manifesting hemorrhagic effusion, swelling, pain, and consequent movement restriction, which might be misdiagnosed. Nowadays, the development of magnetic resonance imaging (MRI) has become an effective and instructive method for diagnosing PVNS. PVNS can be divided into two types [7, 9]: diffuse type and localized type. The localized PVNS is characterized by focal involvement of the synovium, with either nodular or pedunculated masses; the diffuse form involves almost the entire synovium. Both types can occur intra- and/or extra-articular. Although the biology of those two forms is similar, diffuse form is more aggressive clinically [9]. For the treatment of PVNS, both opening and endoscopic management can gain satisfactory patient-reported outcomes. Due to the tumor-like character $[10,11]$ and high recurrence [8] of PVNS, radiotherapy was used widely after synovectomy.

To our best knowledge, this is the first case series study that aim to analyze the clinical outcomes of endoscopic synovectomy with/without radiotherapy postoperatively of PVNS hip.

\section{Method}

This study was a retrospective case series in which all patients underwent arthroscopy at our hospital from November 2010 to February 2021.Inclusion criteria was patients with MRI signs, endoscopic findings, and/or histological evidence of PVNS (Figs. 1 and 2 shows the type of PVNS, Fig. 3 shows the histopathological features). Exclusion criteria was patients lost follow-up. All patients underwent a standard preoperative imaging examination, including hip radiograph and MRI. Basic demographic information, such as age, sex, BMI, symptom duration time, and follow-up period were collected. The degenerative change was evaluated according to Tönnis grading system [12] on an anteroposterior radiograph. Operative treatment for concomitant pathologies, such as femoroacetabular impingement or labral tear, was also recorded. Cartilage injury of the femoral head

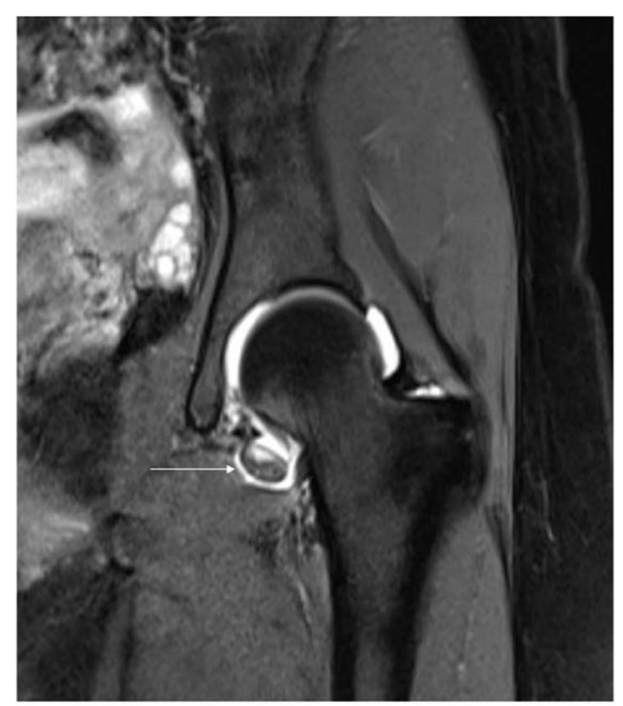

A

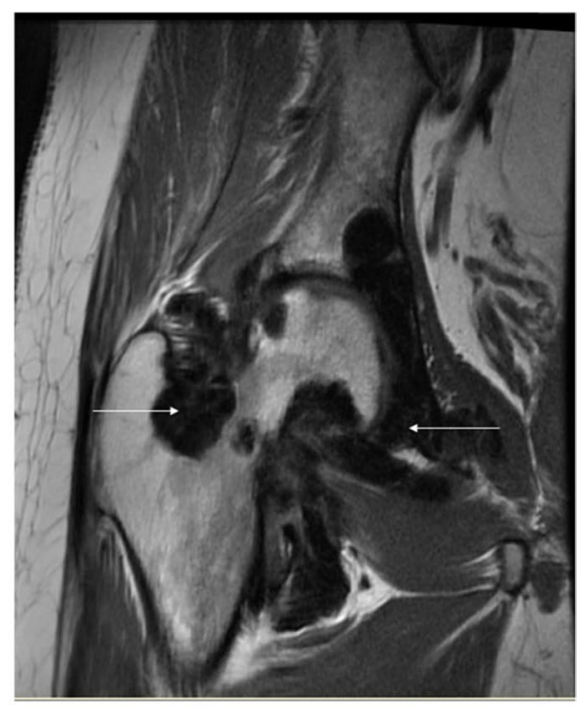

B

Fig. 1 MRI findings of diffuse or localized type of PVNS. A: MRI coronary PD-weighted image of the left hip of localized PVNS, a wide band of short T2 signal nodule can be seen medial to the articular space. B: MRI coronary T1-weighted image of the right hip of diffuse PVNS, multiple long T1 mixed T2 signal shadows can be seen in the articular space. White arrows indicate the lesion sites 


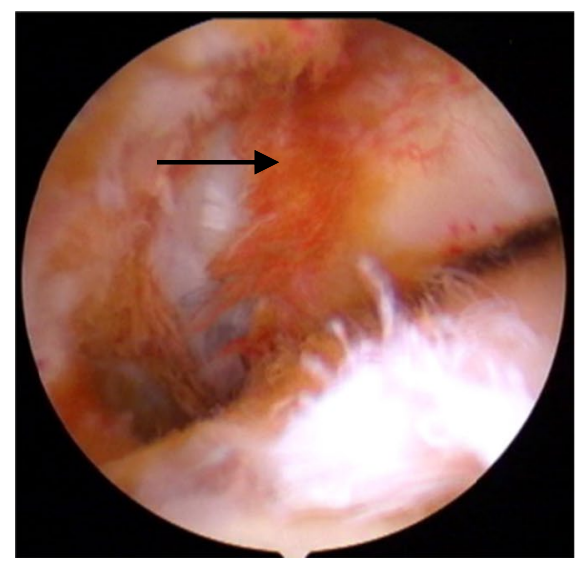

A

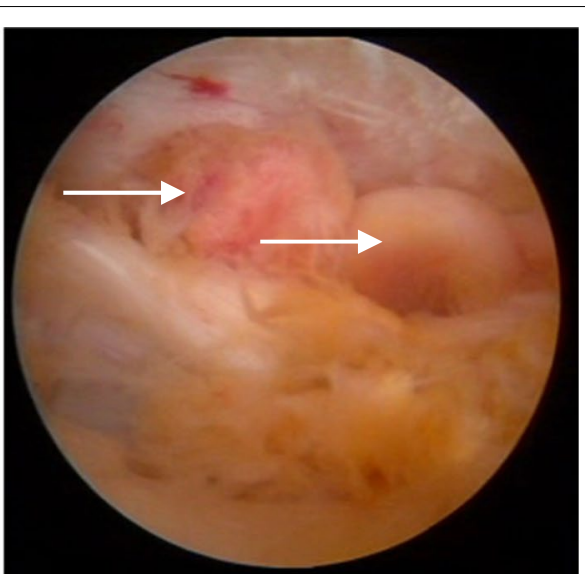

B

Fig. 2 Intraoperative finding of diffuse or localized type of PVNS. Diffuse vs localized (nodular) PVNS lesions. Arthroscopic view of PVNS lesions, which can present as (A) diffuse PVNS lesions (black arrow) to (B) localized (nodular) PVNS lesions (white arrow)

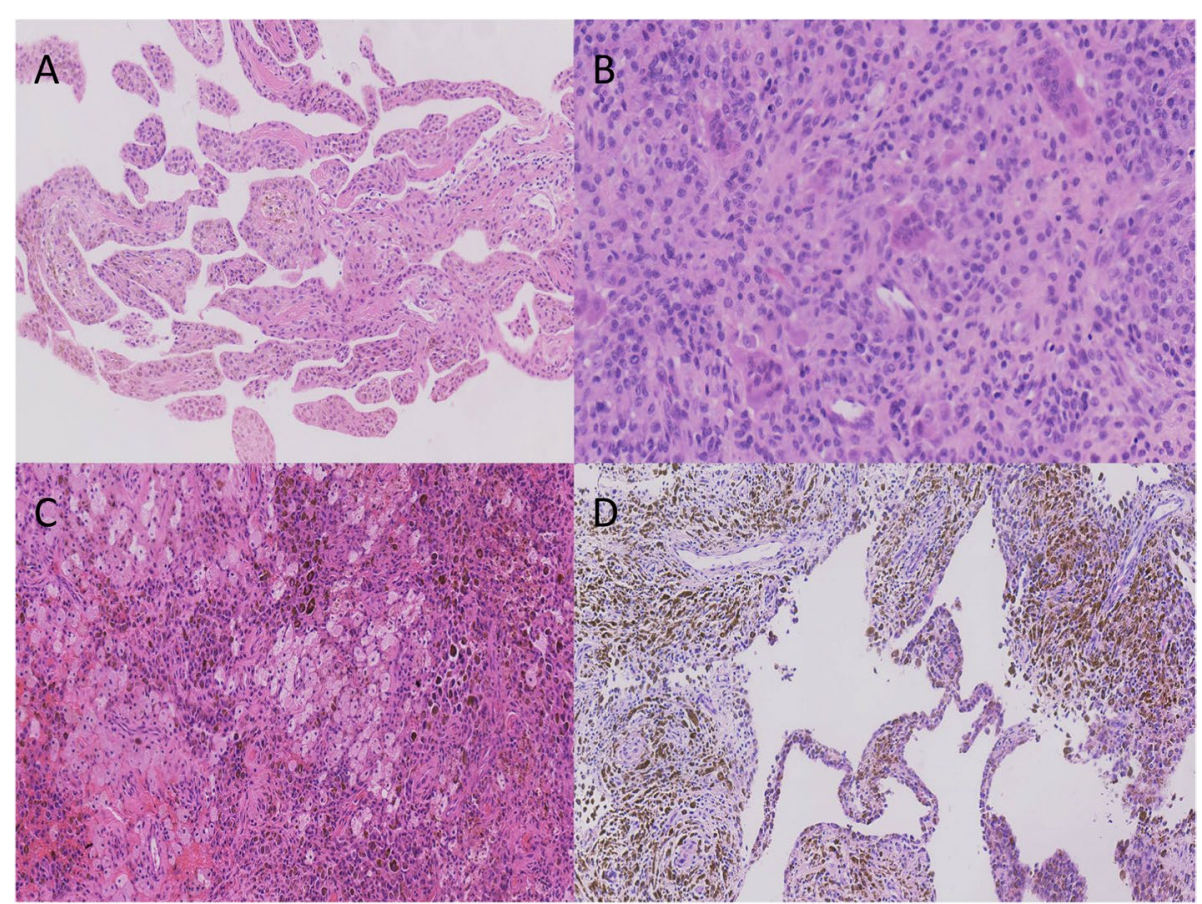

Fig. 3 different histopathological features of PVNS. A. Large amount of villous synovial hyperplasia (HEx 20). B. Homogeneous monocytes associated with scattered multinucleated giant cells (HEx 40). C. Lots of hemosiderin and foam cells (HEx 20). D. Synovial villous hyperplasia and abundant hemosiderin deposition (HEx 20)

and acetabulum were recorded intraoperatively according to the Outerbridge grading system [13]. The size of resected synovium was collected (detailed information in Table 1). Considering the aggressive nature of PVNS, postoperative radiotherapy is recommended. Among patients who did not receive radiotherapy, the main reason was concern about radiotherapy toxicity. For patients who received radiotherapy, the clinical target volumes were defined to cover $5 \mathrm{~mm}$ around the current or original lesion sites. Details of radiotherapy included the using dose, fraction, and the time interval after the operation (Table 2). Radiotherapy was administrated in one session of 7 patients and two sessions of 1 patient. The primary outcome measurements were the recurrence 


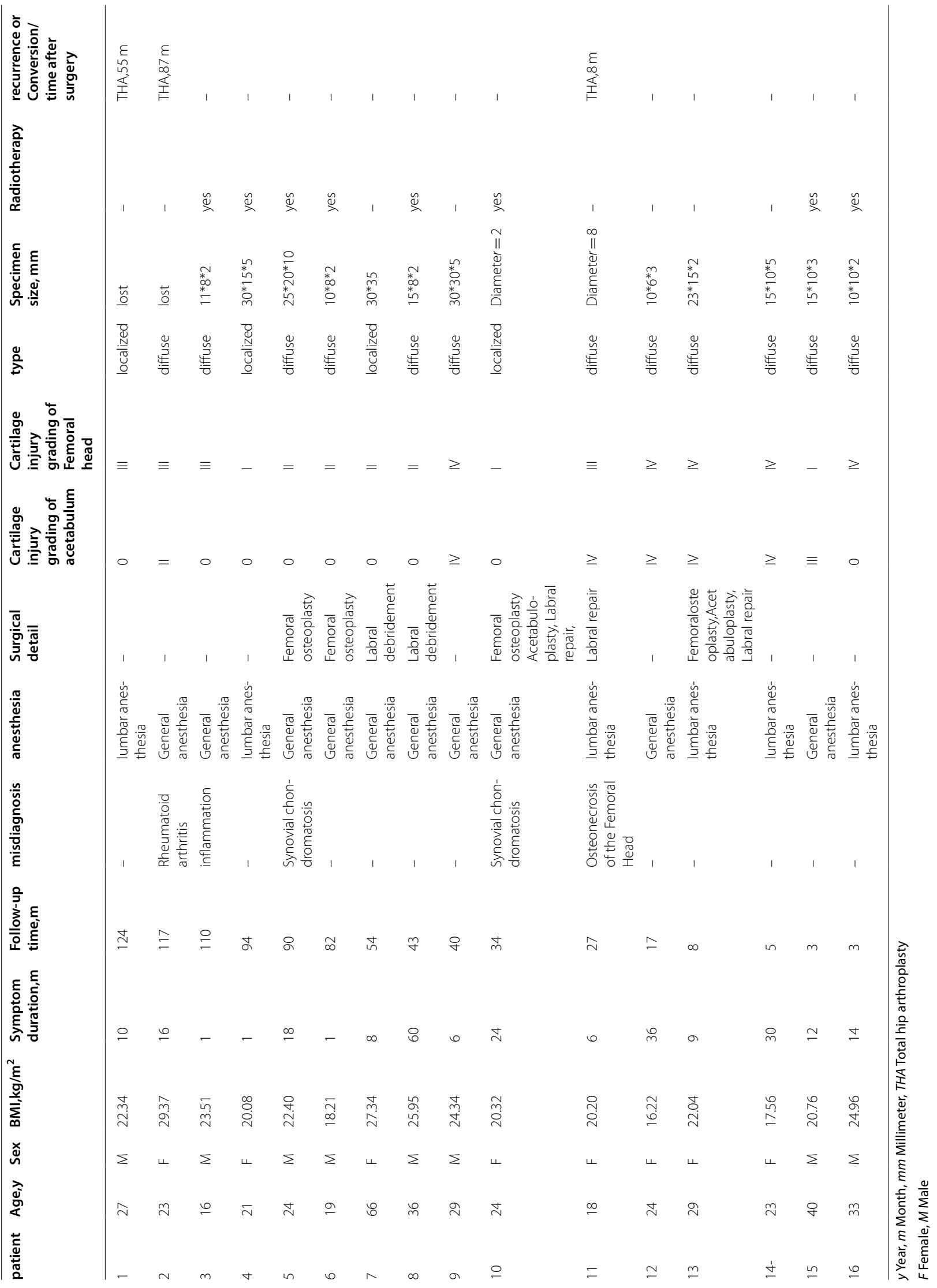


of PVNS, receiving revision, and/or converting to total hip arthroplasty. The secondary outcome measurements were the patient-reported outcome collected at pre- and post-operation, which consist of Hip Outcome Score Activities of Daily Living (HOS-ADL), modified Harris Hip Score (mHHS), International Hip Outcome Tool-12 (IHOT-12), Non-arthritic Hip Scale (NAHS), and visual analog scale (VAS) [14].

\section{Statistical analysis}

Statistical analysis was performed using SPSS software, version 23.0. Categorical variables are represented as a number and percentage, whereas continuous variables are represented by average, standard deviation, and range.

\section{Results}

We retrospectively collected 16 hip PVNS patients (8 cases of female, 50\%) who underwent endoscopy at our hospital. Among those patients, 1 case was misdiagnosed as inflammation, 1 case as rheumatoid arthritis, 1 case as osteonecrosis of the femoral head, 2 cases as synovial chondromatosis, in other medical facilities previously. There were 4 (25\%) cases of localized type and 12 (75\%) cases of diffuse type. All patients underwent synovectomy endoscopically, among which 8 (6 diffuse cases and 2 localized cases,50\%) patients received radiotherapy postoperatively. For the femoral head cartilage injury, 5 cases were degree IV, 4 cases were degree III, 4 cases were degree II, and 3 cases were degree I. And for the acetabular cartilage injury, 5 cases were degree IV, 1 case was degree III, 1 case was degree II, 9 cases had no cartilage injury. All injuries were located at anterosuperior sites of femoral head or acetabulum.

Considering the patients' condition comprehensively, we would recommend adjuvant radiotherapy after surgery. For these patients who didn't receive radiotherapy, most of the reason could be attributed to concerns about the potential effect of radiotherapy, such as fracture, stiffness, carcinoma, and impotence. We, therefore, grouped patients into two groups based on whether they received radiotherapy (RT group) or not (NRT group). Due to long interval after surgery (24 months) of a patient, the patient was not included in the RT group for statistical analysis. At the latest follow-up, no recurrence or revision were in those patients, but 3 cases ( 2 cases of diffuse type and 1 case of localized type) of NRT group converted to THA (Detail in Table 1). All of them had severe multiple bone destruction due to progressing osteoarthritis. For the remaining 13 cases, the mean operative age was 29.5 years (range, 16 to 66 ). The mean BMI was $21.8 \mathrm{~kg} / \mathrm{m}^{2}$ (range,16.2 to 27.3 ). The mean follow-up was 44.8 months (range, 3 to 110 ). The symptom duration time before the operation was 16.9 months (range, 1 to 60) (Detail in Table 3).

The preoperative HOS-ADL, mHHS, IHOT-12, NAHS, VAS scores of remaining 13 patients were $63.1 \pm 19.1$ (range,32.0 to 98.8), $54.8 \pm 20.1$ (range, 10.0 to 77.0 ), $50.9 \pm 15.4$ (range, 31.0 to 76.6 ), $51.6 \pm 15.9$ (range, 20.0 to 84.4 ), $6.0 \pm 1.4$ (range, 4.0 to 8.0 ) points, respectively. The latest HOS-ADL, mHHS, IHOT-12, NAHS, VAS scores of the 13 patients were $79.7 \pm 10.8$ (range, 58.0 to 97.6), $78.6 \pm 9.1$ (range,55.0 to 87.0 ), $74.7 \pm 9.7$ (range, 55.6 to 91.0), $78.9 \pm 18.7$ (range,20.0 to 92.5 ), $3.1 \pm 1.2$ (range,2.0 to 6.0 ) points, respectively. (Detail in Table 4 ).

\section{Discussion}

Although PVNS occurs most commonly in larger joints, it can still arise in other parts of the body, which can be seen in the spine, temporomandibular joint $[15,16]$. Regardless of where PVNS occurs, the traditional treatment is synovectomy, which can be done by opening or endoscopic surgery. Although the opening method has a wider field of view than endoscopic surgery, which can bring the advantage of relatively complete debridement of diseased synovial tissue, it is more invasive than the endoscopic technique. Both two treatments can achieve satisfactory PRO from short- to long-term follow-up [17-19]. A case series study of 14 hips PVNS conducted by Nazal et al. [19] indicated that endoscopic management was an effective method with a survival rate of $93 \%$ (13/14), 1 (7\%) recurrence, and 0 arthroplasty. A retrospective study of 13 hip PVNS cases that underwent arthroscopy reported only 1 case converted to THA at 6 years postoperatively because of progressive osteoarthritis [17]. However, a retrospective study by Schwartz [20] found that the recurrence of treatment for PVNS endoscopically is higher than open surgery, especially for diffuse type. The higher failure rate of treatment for hip PVNS might be explained by periarticular destruction within the closure capsule and the difficulty of surgical resection [21].

Mankin et al. [21] put forward that total hip arthroplasty was the only treatment choice by analyzing 12 cases of hip PVNS treated from 1972 to 2009. However, a retrospective study conducted by Tibbo et al. [22] of case series of 25 PVNS patients who underwent arthroplasty found that the 5- and 10-year survivorship free from any revision were 83 and 63\%, respectively. However, following the THA, 19 patients (76\%) sustained at least 1 complication, most commonly aseptic loosening. Besides, another retrospective study of 16 hip PVNS patients underwent arthroplasty with an average followup of 16.7 years conducted by Vastel et al. [23] reported 1 case of recurrence and 9 cases of revision. Although this suggests that arthroplasty for hip PVNS had a comforting 
recurrence rate, the higher rate of complication in arthroplasty might make endoscopic treatment the preferred choice. In our study, due to continuing progression of osteoarthritis, 3 cases converted to THA eventually. But, compared with other patients' status in our study, patients with more severe joint injury were not converted to THA at the latest follow-up. Previous joint damage might be attributed to secondary injury or PVNS, however, in most conditions, it is hard to explain the outcome when trying to determine whether the symptom might be due to recurrent disease or progression of secondary joint damage [17]. The secondary damage cannot be reversed, nor can it prevent the progression of osteoarthritis. Therefore, based on the condition of affected joints, the surgeon must fully consider the decision to perform less invasive endoscopic surgery or perform total hip arthroplasty.

Because of the infiltrative nature and incomplete resection of PVNS, postoperative adjuvant therapy, such as brachytherapy injection, or external beam radiation, was recommended after resection, especially for diffuse-type PVNS [24]. However, Stephan et al. [25] did not suggest postoperative adjuvant radiotherapy for PVNS patients because of the possible toxic properties of radiotherapy.

A retrospective study of 14 knee PVNS patients who underwent radiotherapy showed 11 patients had good or excellent limb outcomes [26]. A study of 7 PVNS patients (5 knees, 1 hip, 1 wrist) who underwent radical surgery and postoperative radiotherapy showed that 6 patients had asymptomatic limb function and excellent quality of life at average 29 months follow-up [27]. Besides, Horoschak et al. [24] conducted a retrospective study of 17 PVNS patients with 18 lesion sites (12 sites of knee, 3 sites of ankle, 2 sites of hand, and 1 site of spine) treated with postoperative radiotherapy and found that the initial local control rate was $75 \%$ with an average follow-up of 46 months. Furthermore, a study demonstrated that 41 of 50 PVNS patients (20 cases of knee, 9 cases of ankle, 7 cases of foot, 6 cases of hand, 4 cases of hip, 4 cases of wrist) underwent radiotherapy after surgical resection can gain long-term (mean follow-up period of 94 months) good/excellent functio $\mathrm{n}[28]$. No complication or serious complication was found in any of the above studies. It follows that, for the treatment of PVNS patients, postoperative adjuvant radiotherapy might be an effective management that can achieve satisfactory short- to long-term prognosis with no severe complication. However, the optimal dose used for the treatment of PVNS is unclear now. Some studies reported that radiotherapy for PVNS using low dose as 16-20Gy can achieve the outcome of no recurrence [9], whereas other studies using dose as high as $50 \mathrm{~Gy}$ with no complications [26, 27]. In our study, the using dose for PVNS was 10-30 Gy with no complication.

With the persistent development of radiotherapy, the adjuvant method has developed from traditional treatment to three-dimensional conformal radiotherapy(3DCRT), intensity modulated radiotherapy (IMRT), and other novel radiotherapy technologies. Those emerging technologies have the advantages of precise positioning and accurate design.

Radiotherapy has been used widely for refractory cases in the knee joint, but there are few cases in the setting of radiotherapy of hip PVNS exist in the contemporary literature. To our best knowledge, this is the first study aimed to compare the clinical outcomes of hip PVNS patients who underwent CRT or IGRT followed by synovectomy endoscopically with those who received isolated synovectomy. In this study, we found a higher rate of hip joint survivability of the RT group than NRT group, which might provide the evidence that adjuvant radiotherapy treatment after endoscopic synovectomy for hip PVNS can be an effective and safe method.

Table 2 Patients' radiotherapy detail

\begin{tabular}{|c|c|c|c|c|}
\hline patients & Lesion type & Radiotherapy dose/fraction & $\begin{array}{l}\text { First treatment interval after } \\
\text { surgery, } \mathrm{m}\end{array}$ & complications \\
\hline 3 & diffuse & CRT:20Gy/10f & 24 & none \\
\hline 4 & localized & IMRT:12Gy/6f & 1 & none \\
\hline 5 & diffuse & CRT:20Gy/10f & 2 & none \\
\hline 6 & diffuse & CRT:20Gy/10f & 0 & none \\
\hline 8 & diffuse & CRT:20Gy/10f, & 1 & none \\
\hline 10 & localized & CRT:20Gy/10f & 2 & none \\
\hline 15 & diffuse & IMRT:10Gy/5f & 1 & none \\
\hline 16 & diffuse & IMRT:30Gy/15f & 1 & none \\
\hline
\end{tabular}

$m$ Month, CRT Conformal radiotherapy, IMRT Intensity modulated radiotherapy 
Table 3 Demographic characteristics of patients at the latest follow-up

\begin{tabular}{|c|c|c|c|c|c|c|}
\hline & \multicolumn{2}{|l|}{ Total $(n=13)$} & \multicolumn{2}{|c|}{ Radiotherapy $(n=7)$} & \multicolumn{2}{|c|}{ Non-radiotherapy $(n=5)$} \\
\hline & Pre & Post & Pre & Post & Pre & Post \\
\hline HOS-ADL & $\begin{array}{l}63.1 \pm 19.1 \\
(32.0-98.3)\end{array}$ & $\begin{array}{l}79.7 \pm 10.8 \\
(58.0-97.6)\end{array}$ & $\begin{array}{l}61.1 \pm 21.0 \\
(32.0-97.3)\end{array}$ & $\begin{array}{l}81.4 \pm 13.4 \\
(58.0-97.6)\end{array}$ & $\begin{array}{l}69.3 \pm 17.3 \\
(57.4-98.8)\end{array}$ & $76.2 \pm 6.8(67.7-85.0)$ \\
\hline $\mathrm{mHHS}$ & $\begin{array}{l}54.8 \pm 20.1 \\
(10.0-77.0)\end{array}$ & $78.6 \pm 9.1(55.0-87.0)$ & $\begin{array}{l}52.4 \pm 25.4 \\
(10.0-77.0)\end{array}$ & $81.4 \pm 6.3(72.0-87.0)$ & $62.2 \pm 8.1(52.0-71.0)$ & $75.0 \pm 12.5(55.0-87.0)$ \\
\hline iHOT-12 & $\begin{array}{l}50.9 \pm 15.4 \\
(31.0-76.6)\end{array}$ & $74.7 \pm 9.7(55.6-91.0)$ & $\begin{array}{l}55.9 \pm 17.0 \\
(31.0-76.6)\end{array}$ & $\begin{array}{l}75.3 \pm 11.2 \\
(55.6-91.0)\end{array}$ & $\begin{array}{l}45.2 \pm 13.5 \\
(35.0-68.3)\end{array}$ & $73.1 \pm 9.3(64.8-84.0)$ \\
\hline NAHS & $\begin{array}{l}51.6 \pm 15.9 \\
(20.0-84.4)\end{array}$ & $\begin{array}{l}78.9 \pm 18.7 \\
(20.0-92.5)\end{array}$ & $\begin{array}{l}55.1 \pm 16.3 \\
(35.8-84.4)\end{array}$ & $83.0 \pm 7.1(72-92.5)$ & $\begin{array}{l}46.9 \pm 17.8 \\
(20.0-70.0)\end{array}$ & $73.0 \pm 30.0(20.0-91.3)$ \\
\hline VAS & $6.0 \pm 1.4(4.0-8.0)$ & $3.1 \pm 1.2(2.0-6.0)$ & $6.3 \pm 1.1(5.0-8.0)$ & $3.1 \pm 0.9(2.0-4.0)$ & $6.0 \pm 1.6(4.0-8.0)$ & $3.2 \pm 1.6(2.0-6.0)$ \\
\hline
\end{tabular}

$y$ Year, m Month

Table 4 PRO at latest follow-up by radiotherapy or not

\begin{tabular}{|c|c|c|c|c|c|c|}
\hline & \multicolumn{2}{|l|}{ Total $(n=13)$} & \multicolumn{2}{|c|}{ Radiotherapy $(n=7)$} & \multicolumn{2}{|c|}{ Non-radiotherapy $(n=5)$} \\
\hline & Pre & Post & Pre & Post & Pre & Post \\
\hline HOS-ADL & $\begin{array}{l}63.1 \pm 19.1 \\
(32.0-98.3)\end{array}$ & $\begin{array}{l}79.7 \pm 10.8 \\
(58.0-97.6)\end{array}$ & $\begin{array}{l}61.1 \pm 21.0 \\
(32.0-97.3)\end{array}$ & $\begin{array}{l}81.4 \pm 13.4 \\
(58.0-97.6)\end{array}$ & $\begin{array}{l}69.3 \pm 17.3 \\
(57.4-98.8)\end{array}$ & $76.2 \pm 6.8(67.7-85.0)$ \\
\hline $\mathrm{mHHS}$ & $\begin{array}{l}54.8 \pm 20.1 \\
(10.0-77.0)\end{array}$ & $78.6 \pm 9.1(55.0-87.0)$ & $\begin{array}{l}52.4 \pm 25.4 \\
(10.0-77.0)\end{array}$ & $81.4 \pm 6.3(72.0-87.0)$ & $62.2 \pm 8.1(52.0-71.0)$ & $75.0 \pm 12.5(55.0-87.0)$ \\
\hline iHOT-12 & $\begin{array}{l}50.9 \pm 15.4 \\
(31.0-76.6)\end{array}$ & $74.7 \pm 9.7(55.6-91.0)$ & $\begin{array}{l}55.9 \pm 17.0 \\
(31.0-76.6)\end{array}$ & $\begin{array}{l}75.3 \pm 11.2 \\
(55.6-91.0)\end{array}$ & $\begin{array}{l}45.2 \pm 13.5 \\
(35.0-68.3)\end{array}$ & $73.1 \pm 9.3(64.8-84.0)$ \\
\hline NAHS & $\begin{array}{l}51.6 \pm 15.9 \\
(20.0-84.4)\end{array}$ & $\begin{array}{l}78.9 \pm 18.7 \\
(20.0-92.5)\end{array}$ & $\begin{array}{l}55.1 \pm 16.3 \\
(35.8-84.4)\end{array}$ & $83.0 \pm 7.1(72-92.5)$ & $\begin{array}{l}46.9 \pm 17.8 \\
(20.0-70.0)\end{array}$ & $73.0 \pm 30.0(20.0-91.3)$ \\
\hline VAS & $6.0 \pm 1.4(4.0-8.0)$ & $3.1 \pm 1.2(2.0-6.0)$ & $6.3 \pm 1.1(5.0-8.0)$ & $3.1 \pm 0.9(2.0-4.0)$ & $6.0 \pm 1.6(4.0-8.0)$ & $3.2 \pm 1.6(2.0-6.0)$ \\
\hline
\end{tabular}

RT Radiotherapy, NRT Non-radiotherapy

\section{Limitation}

There are several important limitations of this study. First, though the size of the sample is relatively large for known reports of a single center, the total sample size was still small, and there is a bias in patients' choice of radiotherapy, thus more patients were needed to compare the results. Second, though satisfactory average mid-term PRO gained in our study, the long-term outcome remains to be seen. Third, the time span of this study was more than 11 years, which may affect the outcomes because of the improvement of surgery and radiotherapy technology. Fourth, treatment for concomitant pathology were performed, which made it difficult to distinguish whether the improved PRO was due to the treatment of PVNS or other hip lesions.

\section{Conclusion}

Endoscopic synovectomy can achieve satisfactory PRO. Besides, postoperative adjuvant radiotherapy can achieve higher hip survivability than synovectomy alone in this present study.

\section{Abbreviations}

PVNS: Pigmented villonodular synovitis; MRI: Magnetic resonance image; THA: Total hip arthroplasty; PRO: Patient-reported outcome; HOS-ADL: Hip Outcome Score Activities of Daily Living; mHHS: Modified Harris Hip Score; IHOT-12: International Hip Outcome Tool-12; NAHS: Non-arthritic Hip Scale; VAS: Visual analog scale; CRT: Conformal radiotherapy; IMRT: Intensity modulated radiotherapy; RT: Radiotherapy; NRT: Non-radiotherapy.

\section{Acknowledgements}

Thanks to all participating authors for their contributions and we are grateful to Dr. Hong-Qing Zhuang, who provided the relative information about radiotherapy details.

\section{Authors' contributions}

XDJ and JQW designed the study. XDJ and HS collected and interpreted the data. H S was a contributor in writing the manuscript. HJH and XZ performed the spelling and grammar correction. All authors read and approved the final manuscript.

\section{Funding}

The full official funding agency name should be given:

National Natural Science Foundation of China (Grant Nos. 82072403).

National Natural Science Foundation of China (Grant Nos. 81871761).

\section{Availability of data and materials}

The datasets used and/or analyzed during the current study are available from the corresponding author on reasonable request. 


\section{Declarations}

\section{Ethics approval and consent to participate}

The study was approved by the ethics committee (Peking University Third Hospital Medical Science Research Ethics Committee). This study was a retrospective study and an informed exemption application was obtained from (Peking University Third Hospital Medical Science Research Ethics Committee). All methods were carried out in accordance with relevant guidelines and regulations.

\section{Consent for publication}

All authors agreed to publish.

\section{Competing interests}

The authors declare that they have no competing interests" in this section.

Received: 2 November 2021 Accepted: 7 February 2022

Published online: 02 March 2022

\section{References}

1. Chassaignac CM. Cancer de la gaine des tendons [cancer of the tendon sheath]. Gaz Hop Civ Milit. 1852:47:185-6.

2. Jaffe HL, Lichtenstein L, Sutro CJ. Pigmented villonodular synovitis, bursitis and tenosynovitis a discussion of the synovial and bursal equivalents of the tenosynovial lesion commonly denoted as xanthoma, xanthogranuloma, giant cell tumor or myeloplaxoma of the tendon sheath, with some consideration of this tendon sheath lesion itself. Arch Pathol. 1941;31(6):731-65.

3. Docken WP. Pigmented villonodular synovitis: a review with illustrative case reports. Semin Arthritis Rheum. 1979;9(1):1-22.

4. Goldman AB, DiCarlo EF. Pigmented villonodular synovitis. Diagnosis and differential diagnosis. Radiol Clin N Am. 1988;26(6):1327-47.

5. Dorwart RH, Genant HK, Johnston WH, Morris JM. Pigmented villonodular synovitis of synovial joints: clinical, pathologic, and radiologic features. AJR Am J Roentgenol. 1984;143(4):877-85.

6. van der Heijden L, Piner SR, van de Sande MA. Pigmented villonodular synovitis: a crowdsourcing study of two hundred and seventy two patients. Int Orthop. 2016;40(12):2459-68.

7. Myers BW, Masi AT. Pigmented villonodular synovitis and tenosynovitis: a clinical epidemiologic study of 166 cases and literature review. Medicine (Baltimore). 1980;59(3):223-38.

8. Xie GP, Jiang N, Liang CX, et al. Pigmented villonodular synovitis: a retrospective multicenter study of 237 cases. PLoS One. 2015;10(3):e0121451.

9. Granowitz SP, D'Antonio J, Mankin HL. The pathogenesis and long-term end results of pigmented villonodular synovitis. Clin Orthop Relat Res. 1976:114:335-51.

10. Cassier PA, Gelderblom H, Stacchiotti S, et al. Efficacy of imatinib mesylate for the treatment of locally advanced and/or metastatic tenosynovial giant cell tumor/pigmented villonodular synovitis. Cancer. 2012;118(6):1649-55.

11. Yoon HJ, Cho YA, Lee Jl, Hong SP, Hong SD. Malignant pigmented villonodular synovitis of the temporomandibular joint with lung metastasis: a case report and review of the literature. Oral Surg Oral Med Oral Pathol Oral Radiol Endod. 2011;111(5):e30-6.

12. Tonnis D. Normal values of the hip joint for the evaluation of $x$-rays in children and adults. Clin Orthop Relat Res. 1976;119:39-47.

13. Outerbridge RE. The etiology of chondromalacia patellae. J Bone Joint Surg Br. 1961;43:B752-7.

14. Stone AV, Jacobs CA, Luo TD, et al. High degree of variability in reporting of clinical and patient-reported outcomes after hip arthroscopy. Am J Sports Med. 2018:46(12):3040-6.

15. Oh SW, Lee MH, Eoh W. Pigmented villonodular synovitis on lumbar spine : a case report and literature review. J Korean Neurosurg Soc. 2014;56(3):272-7

16. Yang $X$, Sun $Y, Y u$ W, Fu J. Pigmented villonodular synovitis of the temporomandibular joint: case report and the literature review for postoperative radiotherapy. J Radiol Case Rep. 2019;13(8):31-9.
17. Byrd JW, Jones KS, Maiers GP 2nd. Two to 10 years' follow-up of arthroscopic management of pigmented villonodular synovitis in the hip: a case series. Arthroscopy. 2013;29(11):1783-7.

18. Hufeland M, Gesslein M, Perka C, Schroder JH. Long-term outcome of pigmented villonodular synovitis of the hip after joint preserving therapy. Arch Orthop Trauma Surg. 2018;138(4):471-7.

19. Nazal MR, Parsa A, Gibbs JS, Abraham PF, Martin SD. Mid-term results of arthroscopic synovectomy for pigmented villonodular synovitis of the hip. Arthroscopy. 2020;36(6):1587-98.

20. Schwartz HS, Unni KK, Pritchard DJ. Pigmented villonodular synovitis. A retrospective review of affected large joints. Clin Orthop Relat Res. 1989;(247):243-55

21. Mankin H, Trahan C, Hornicek F. Pigmented villonodular synovitis of joints J Surg Oncol. 2011;103(5):386-9.

22. Tibbo ME, Wyles CC, Rose PS, Sim FH, Houdek MT, Taunton MJ. Long-term outcome of hip arthroplasty in the setting of pigmented villonodular synovitis. J Arthroplast. 2018;33(5):1467-71.

23. Vastel L, Lambert P, De Pinieux G, Charrois O, Kerboull M, Courpied JP. Surgical treatment of pigmented villonodular synovitis of the hip. J Bone Joint Surg Am. 2005:87(5):1019-24.

24. Horoschak M, Tran PT, Bachireddy P, et al. External beam radiation therapy enhances local control in pigmented villonodular synovitis. Int J Radiat Oncol Biol Phys. 2009;75(1):183-7.

25. Stephan SR, Shallop B, Lackman R, Kim TW, Mulcahey MK. Pigmented villonodular synovitis: a comprehensive review and proposed treatment algorithm. JBJS Rev. 2016;4(7):e3.

26. O'Sullivan BCummings BCatton $\mathrm{C}$, et al. Outcome following radiation treatment for high-risk pigmented villonodular synovitis. Int J Radiat Oncol Biol Phys. 1995;32(3):777-86.

27. Berger B, Ganswindt U, Bamberg M, Hehr T. External beam radiotherapy as postoperative treatment of diffuse pigmented villonodular synovitis. Int J Radiat Oncol Biol Phys. 2007;67(4):1130-4.

28. Griffin AM, Ferguson PC, Catton CN, et al. Long-term outcome of the treatment of high-risk tenosynovial giant cell tumor/pigmented villonodular synovitis with radiotherapy and surgery. Cancer. 2012;118(19):4901-9.

\section{Publisher's Note}

Springer Nature remains neutral with regard to jurisdictional claims in published maps and institutional affiliations.

Ready to submit your research? Choose BMC and benefit from:

- fast, convenient online submission

- thorough peer review by experienced researchers in your field

- rapid publication on acceptance

- support for research data, including large and complex data types

- gold Open Access which fosters wider collaboration and increased citations

- maximum visibility for your research: over 100M website views per year

At BMC, research is always in progress.

Learn more biomedcentral.com/submissions 